\title{
Laudation for Professor Kattesh V. Katti Hevesy Medal Awardee 2015
}

\author{
A. Chatt ${ }^{1}$
}

Published online: 24 May 2016

(C) Akadémiai Kiadó, Budapest, Hungary 2016

Kattesh Katti was born in Karnataka, India, in 1956. He received his BSc in Chemistry from Karnataka University in 1977, Masters in Science Education from University of Mysore in 1979, and PhD in Inorganic Chemistry in 1984 from the Indian Institute of Science. He was an Alexander Von Humboldt Postdoctoral Fellow in Gottingen, Germany (1985-1987) and a Research Associate at the University of Alberta (1987-1989). He received an Honorary Doctor of Science (DSc) from Karnataka University in 2009 and a second Honorary DSc from Sam Higginbottom University in 2012.

Dr. Katti started his professional career as a Research Associate at the University of Alberta (1989-1990). In 1990 he joined the University of Missouri at Columbia as a Research Assistant Professor of Radiology. He became a Professor of Radiology there in 2002. He holds several other senior positions in the departments of Physics, Chemistry, Biological Engineering, Radiopharmaceutical Sciences Institute, and in Research Reactor, Radiochemistry and Bioconjugation Core Facility, Nanoparticle Production Core Facility, etc. at the University of Missouri.

Over the last 25 years or so, Prof. Katti has excelled in many research frontiers. For example, he developed the first phosphine based Tc-labeled bifunctional chelating agents and demonstrated its utility in nuclear medicine for SPECT imaging of tumors. He developed novel methods for the production of therapeutic radioisotopes including ${ }^{188 / 186} \mathrm{Re},{ }^{109} \mathrm{Pd},{ }^{105} \mathrm{Rh},{ }^{198 / 199} \mathrm{Au}$. His hydroxymethyl

\section{A. Chatt}

chatt@dal.ca

1 Department of Chemistry, Trace Analysis Research Centre, Dalhousie University, 6274 Coburg Road, Room 212, P.O. Box 15000, Halifax, NS B3H 4R2, Canada functionalized water-soluble phosphines are currently used extensively in nuclear medicine research throughout the world. Prof. Katti's research marked the genesis for the production of well-defined nanoparticles of ${ }^{198} \mathrm{Au}$ and ${ }^{199} \mathrm{Au}$ through interactions of his phosphine-amino acid trimeric frameworks with radioactive gold chloride. His latest discoveries in green nanotechnology have provided an open window for the application of biocompatible radioactive gold nanoparticles in molecular imaging and therapy.

Prof. Katti has coauthored over 20 book chapters, reviews and monographs. He has over 260 peer-reviewed publications, reviews, invited monographs and over 50 patents. He has been a plenary speaker at $300+$ major national/international meetings in over 25 countries around the globe. He was the supervisor of many postdoctoral fellows, and $\mathrm{PhD}$ as well as MSc students. He taught several courses also.

In 2013 Prof. Katti was elected as a Fellow of the American Association for the Advancement of Science (AAAS). Prof. Katti has received numerous international and national prestigious awards. These include the Gauss Professorship by Gottingen Academy of Sciences in 2008; "One of 25 Most Influential Scientists in Molecular Imaging in the world" by RT Image in 2009; "One of the Seven Best Nanomedicine Scientists in the world" by HemOnc Today in 2013; "Fellow of the St Louis Academy of Science" in 2013; "Outstanding Missourian Award" by the Missouri House of Representatives in 2008; Distinguished Curators' Professorship Award by the University of Missouri in 2009; an institute after his name as 'Kattesh Katti Institute of Green Nanotechnology and Agri Nanotechnology" at Sam Higginbottom University in 2014. In 2015, Prof. Katti was elected to the fellowship of the National Academy of Inventors (NAI) as a fellow of the 
Fig. 1 From left to right: Dr. Antonia Denkova, Prof. Amares Chatt, Prof. Kattesh Katti, Dr. Peter Bode, and Dr. Zsolt Revay

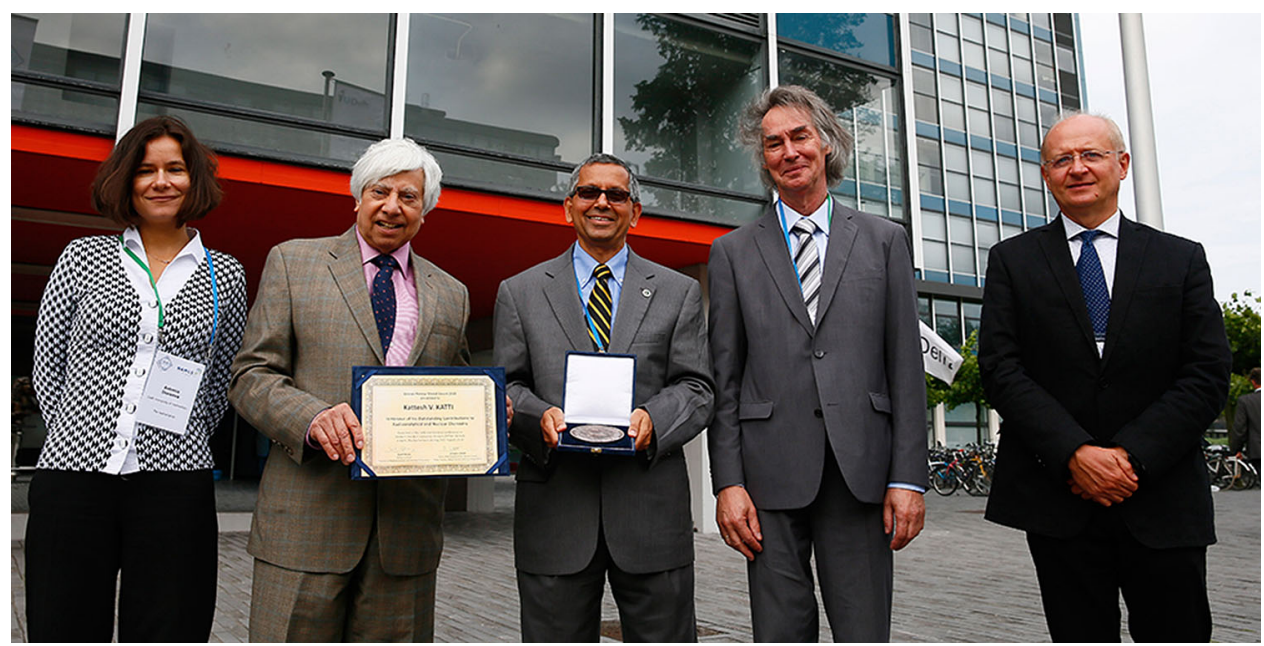

National Academy of Inventors in recognition of his seminal inventions, numerous patents and products.

It is indeed a pleasure to honor Prof. Kattesh V. Katti of the Center for Radiological Research, University of Missouri-Columbia, Columbia, MO, U.S.A. with the Hevesy Medal Award 2015 in recognition of his innovative contributions in the fields of radiopharmaceuticals and toward the development of nanomedicine products.

The Hevesy Medal Award Selection Panel 2015 (HMASP-15) consisted of Professor Amares Chatt (Dalhousie University, Canada; also Chair of JRNC Board of the Hevesy Award, and Chair of HMASP-15), Dr. Peter Bode (Delft University of Technology, The Netherlands; also representing MTAA-14), Professor Zhifang Chai (Chinese Academy of Sciences, China), Dr. Sam Glover (National Institute for Occupational Safety and Health,
U.S.A.; also representing MARC-X), Professor Jan John (Czech Technical University in Prague, Czech Republic), Dr. Richard M. Lindstrom (National Institute of Standards and Technology, U.S.A.), Professor Boris F. Myasoedov (Russian Academy of Sciences, Russia), Professor Syed Qaim (Forschungszentrum Juelich GmbH, Juelich, Germany), and Dr. Zsolt Revay (Technische Universität München, Germany; also representing JRNC). In accordance with the rules of the Award, a secret vote was conducted.

The Hevesy Medal and a Scroll were presented to Professor Katti at the Fourteenth International Conference on Modern Trends in Activation Analysis (MTAA-14) held at the Delft University of Technology, Delft, The Netherlands during 2015 August 23-28 (Fig. 1). 